Pacific Journal of Mathematics

GENERALIZED CHARACTER SEMIGROUPS: THE SCHWARZ 


\title{
GENERALIZED CHARACTER SEMIGROUPS: THE SCHWARZ DECOMPOSITION
}

\author{
Y.-F. LIN
}

The author's résumé: A structure theorem due to S. Schwarz asserts that if $S$ is a finite abelian or a compact abelian semigroup admitting relative inverses, than the character semigroup of $S$ is decomposed into a disjoint union of character groups of certain maximal subgroups of $S$. In this note, among other things, we generalize this Schwarz Decomposition Theorem to a broader class of semigroups, the so-called pseudo-invertible semigroups. We also relax the range of the characters from the semigroup of complex numbers to a more general semigroup.

For notations and terms not defined here see A. D. Wallace [11].

Throughout this paper, let $S$ be always a compact commutative semigroup, unless otherwise stated. By a character of $S$ is meant a continuous homomorphism of $S$ into the multiplicative semigroup $C$ of the complex numbers endowed with the usual Euclidean topology. The collection of all characters of $S$, with the value-wise multiplication of functions, endowed with the compact-open topology, forms a semigroup which will be denoted by $(S, C)^{\wedge}$ or simply $S^{\wedge}$, and will be called the character semigroup of $S$. Hewitt and Zuckerman [4] use the term semicharacter, in the discrete case, for not identically zero characters. Here we use $(\hat{S}, C)$ or simply $\hat{S}$, as distinguished from $S^{\wedge}$, to denote the collection of semicharacters of $S$. We note that $\widehat{S}$, in general, need not be a semigroup. We first draw attention to the fact that if $\chi$ is a character of $S$, then $|\chi(x)| \leqq 1$ for every $x$ in $S$. For, otherwise $\chi(S)$ would not be compact. Thus, in the study of characters, only the unit $\operatorname{disc}\{z:|z| \leqq 1\}$ of the complex numbers is used. Let us write $D$ for this unit disc. The set $D$ itself forms an important semigroup which is compact, connected, commutative, cancellable, ${ }^{1}$ has zero 0 and unit 1 ; moreover the circumference $\{z:|z|=1\}$ of $D$ is the maximal subgroup $H(1)$ and $D \backslash H(1)$ is an ideal. However, only some of these are needed as we shall see below.

Throughout the rest of this paper, let $T$ be an arbitrary, but fixed, compact commutative cancellable semigroup with zero $z$ and unit $u^{2}$ such that $T \backslash H(u)$ is a subsemigroup of $T$. By a generalized character

1 A semigroup $S$ is cancellable if and only if for any nonzero elements $a, b, c$ in $S$ such that $a b=a c$ or $b a=c a$, then $b=c$.

${ }^{2}$ It is to be understood that $z \neq u$.

Received August 27, 1964. 
of $S$ is meant a continuous homomorphism of $S$ to $T$. As in the case of character semigroup, the collection $(S, T)^{\wedge}$ of all generalized characters of $S$, with value-wise multiplication of mappings and the compactopen topology, forms a commutative (topological) semigroup which will be called the generalized character semigroup of $S$. We write $(\hat{S}, T)$ for the collection of all not identically zero elements in $(S, T)^{\wedge}$. It is quite easy to see that if $S$ is a group, then $(\hat{S}, T)=(\hat{S}, H(u))$ and $(\widehat{S}, T)$ is a group.

\section{THEOREM 1. If $S$ is discrete, then $(S, T)^{\wedge}$ is compact.}

Proof. Since $S$ is discrete, the compact-open topology on $(S, T)^{\wedge}$ is the relative topology, on the set (not topologized) $(S, T)^{\wedge}$, of the Tychonoff product topology on the product $P\{T: s \in S\}$, which is compact by the Tychonoff theorem. The compactness of $(S, T)^{\wedge}$ now follows from the fact that $(S, T)^{\wedge}$ is a closed subset of $P\{T: s \in S\}$.

Definition 1. For any $\chi$ in $(S, T)^{\wedge}$, the support of $\chi, s p(\chi)$, is the set $\{x: x \in S, \chi(s) \neq z\}$.

We have immediately $s p\left(\chi_{1} \cdot \chi_{2}\right)=s p\left(\chi_{1}\right) \cap s p\left(\chi_{2}\right)$ for any $\chi_{1}, \chi_{2}$ in $(S, T)^{\wedge}$. It is clear that if $\chi$ in $(S, T)^{\wedge}$ is not identically zero, $s p(\chi)$ is an open subsemigroup of $S$; such an open subsemigroup will be called a supporting subsemigroup. Since the support of the zero generalized character is the void set $\square$, as a convenience we also call $\square$ a supporting subsemigroup. We write henceforth, $\mathscr{P}(S)$ or $\mathscr{P}$ for the collection of all supporting subsemigronps of $S$.

DEFinition 2 [8]. The Rees partial-ordering $\leqq$ on the set $E$ of idempotents in $S$ is the subset $\left\{\left(e_{1}, e_{2}\right):\left(e_{1}, e_{2}\right) \in E \times E, e_{1} e_{2}=e_{1}\right\}$. If $\left(e_{1}, e_{2}\right)$ is in $\leqq$ we write, equivalently, $e_{1} \leqq e_{2}$.

Lemma 0 [13]. Let $(X, \leqq)$ be a nonvoid compact topological space endowed with a quasi-ordering $\leqq$ such that for each $t$ in $X$ the set $\{x: x \in X, x \leqq t\}$ is closed in $X$. Then $(X, \leqq)$ has a minimal element.

Proof. See Ward [13, Theorem 1].

Lemma 1. If $S_{0}$ is a compact subsemigroup of $S$, then $E\left(S_{0}\right)$ has a unique minimal element with respect to the Rees partialordering $\leqq$.

Proof. Since $S_{0}$ is a compact semigroup, the set $E\left(S_{0}\right)$ of all idempotents in $S_{0}$ is a nonvoid closed subset of $S_{0}$. It is fairly easy 
to see that $\left\{x: x \in E\left(S_{0}\right), x \leqq \mathrm{t}\right\}$ is closed for each $t$ in $E\left(S_{0}\right)$. It then follows from Lemma 0 that $\left(E\left(S_{0}\right), \leqq\right)$ has a minimal element, say $e_{0}$. If there were another minimal element $e_{1}$ in $E\left(\mathbb{S}_{0}\right)$, then one concludes $e_{1}=e_{0} e_{1}=e_{0}$. This proves the uniqueness.

Definition 3. If $P \in \mathscr{P}(S)$, then $\sigma(P)$ is the set

$$
\left\{\chi: \chi \in(S, T)^{\wedge}, \operatorname{sp}(\chi)=P\right\} \text {. }
$$

For each $P$ in $\mathscr{P}(S), \sigma(P)$ is easily seen to be a cancellable subsemigroup of $(S, T)^{\wedge}$. In general, $(S, T)^{\wedge}$ may be decomposed into the union of the disjoint family $\{\sigma(P): P \in \mathscr{P}(S)\}$ of cancellable subsemigroups of $(S, T)^{\wedge}$.

DeFinition 4 [1]. A semigroup $S$ admitting relative inverses is a semigroup such that to each $x$ in $S$ there is a pair $\left(e, x^{\prime}\right)$ in $E \times S$ such that $x e=x=e x$ and $x x^{\prime}=e=x^{\prime} x$.

A well-known result of $\mathrm{A}$. H. Clifford [1] says that a semigroup is a semigroup admitting relative inverses if and only if it is the disjoint union of its maximal subgroups. The more general class of semigroups that we are interested in is the following.

Definition 5 [3]. A semigroup $S$ is pseudo-invertible if and only if, to each element $x$ in $S$ there is an $\bar{x}$ in $S$ such that

(i ) $x \bar{x}=\bar{x}$;

(ii) $\bar{x} x^{n+1}=x^{n}$ for some positive integer $n$, and

(iii) $\bar{x}^{2} x=\bar{x}$.

The element $\bar{x}$ satisfying conditions (i), (ii) and (iii) above turns out to be unique if it exists [3], in which case it is called the pseudoinverse of $x_{0}$ A semigroup $S$ is pseudo-invertible if and only if, to every $x$ in $S$ there is an integer $n>0$ such that $x^{n}$ is in some subgroup of $S$ [3], [5], [6]. From this, one sees that the class of pseudoinvertible semigroups includes all semigroups admitting relative inverses, all periodic semigroups; all semigroups of matrices; all finite dimensional affine semigroups (for definition of an affine semigroup, see [2]) and many others.

LEMMA 2. Let $S$ be a compact commutative pseudo-invertible semigroup. Then each supporting subsemigroup $P$ of $S$ is open and closed. Therefore, if $P \neq \square$ then $P$ has a unique minimal idempotent $e_{P}$ with respect to the Rees partial-ordering on $E(P)$. 
Proof. To show each $P$ in $\mathscr{P}$ is open and closed, we may consider only $P \neq \square$. For any nonvoid $P$ in $\mathscr{P}$, there is a $\chi$ in $(S, T)^{\wedge}$ such that $P=\{x: x \in S, \chi(x) \neq z\}$. We show, for pseudo-invertible $S$, also, $P=\{x: x \in S, \chi(x) \in H(u)\}$ and consequently $P$ is open and closed. To this end, let $x$ be an arbitrary element of the nonvoid set $P=$ $\{x: x \in S, \chi(x) \neq z\}$. Then since $S$ is pseudo-invertible, there is a positive integer $n$ such that $x^{n} \in H(e)$ for some $e$ in $E$; thus, since $E(T)=$ $\{z, u\}$, we must have $\chi(x)^{n}=\chi\left(x^{n}\right) \in H(u)$. Consequently, since $T \backslash H(u)$ is a subsemigroup, we obtain $\chi(x) \in H(u)$. This proves

$$
\{x: x \in S, \chi(x) \neq z\}=P=\{x: x \in S, \chi(x) \in H(u)\},
$$

so that $P$ is open and closed

The set $P$ being a closed subsemigroup of the compact semigroup $S$, by Lemma $1, E(P)$ has a unique minimal element $e_{P}$ with respect to the Rees partial ordering.

In the following, for $Q \subset S, e_{Q}$ will be the least idempotent in $Q$ if it exists.

THEOREM 2. Let $S$ be a compact commutative pseudo-invertible semigroup. Then the generalized character semigroup $(S, T)^{\wedge}$ of $S$ may be decomposed into the union of the disjoint family $\left\{\left(\hat{H\left(e_{P}\right)}, T\right): P \in \mathscr{P}\right\}$ of groups, where we agree that $\left(\hat{H}_{\square}, T\right)=\{0\}$.

The proof of this theorem is contained in the following two lemmas. It should be noted that when $T \subset C,(\hat{H(e)}, T)$ is the familiar character group $\hat{H(e)}$.

LEMMA 3. Under the hypothesis of Theorem 2, for any nonvoid $P$ in $\mathscr{P}(S)$, the maximal subgroup $H\left(e_{P}\right)$ of $S$ is the kernel of $P$; and the mapping $r_{P}: P \rightarrow H\left(e_{P}\right)$ which takes every $x$ in $P$ to $x e_{P}$ is a (continuous) retraction of $P$ onto $H\left(e_{P}\right)$.

Proof. Let $x$ be an arbitrary element of $S$. Let $\Gamma(x)=\left\{x^{n}: n \geqq 1\right\}^{-}$ and $N(x)=\cap\left\{x^{n} \Gamma(x): n \geqq 1\right\}$, then $N(x)$ is the kernel of $\Gamma(x)$ as well as, since $S$ is compact, a closed subgroup of $S$. Thus $N(x)$ contains a unique idempotent which is designated simply by $e_{x}$ instead of the rather complicated aymbol $e_{N(x)}$. If $x$ is in $P$ we have $e_{x} e_{P}=e_{P}$ and hence the unique idempotent in $N\left(x e_{P}\right)$ is $e_{P}$. Therefore, $x e_{P}=$ $\left(x e_{P}\right) e_{P} \in N\left(x e_{P}\right) \subset H\left(e_{P}\right)$ for all $x$ in $P$. To show $H\left(e_{P}\right)$ is an ideal of $P$, we first show that $H\left(e_{P}\right) \subset P$. This is true since there is a $\chi_{P}$ in $(S, T)^{\wedge}$ such that an element $x$ of $S$ is in $P$ if and only if $\chi_{P}(x) \neq z$; 
so $\chi_{P}\left(e_{P}\right) \neq z$ (consequently $\chi_{P}\left(e_{P}\right)=u$ ) and thus $\chi_{P}(x) \neq z$ for all $x$ in $H\left(e_{P}\right)$. Now $P H\left(e_{P}\right)=P H\left(e_{P}\right) e_{P} \subset P e_{P} \subset H\left(e_{P}\right)$ shows that $H\left(e_{P}\right)$ is an ideal of $P$; since it is a group it must be the minimal ideal of $P$. The fact that $r_{P}: P \rightarrow H\left(e_{P}\right)$ is a continuous retraction onto is then evident.

LEMma 4. Under the hypothesis of Theorem 2, for any nonvoid $P$ in $\mathscr{P}(S), \sigma(P)=\left\{\chi: \chi \in(S, T)^{\wedge}, \operatorname{sp}(\chi)=P\right\}$ is isomorphic to the generalized character group $\left.\left(\hat{H(} e_{P}\right), T\right)$ of the maximal subgroup $H\left(e_{P}\right)$ of $S$. In particular, if $T \subset C, \sigma(P)$ is also homeomorphic with the

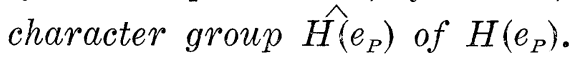

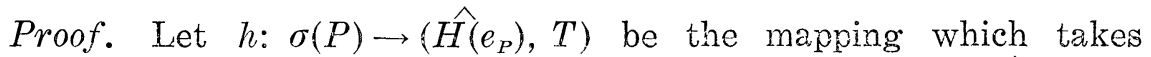
each $\chi$ in $\sigma(P)$ to $\chi \mid H\left(e_{P}\right)$. Clearly $\chi \in \sigma(P)$ implies $\chi \mid H\left(e_{P}\right) \in\left(\hat{\left.H\left(e_{P}\right), T\right)}\right.$. We have $h\left(\chi_{1} \cdot \chi_{2}\right)=\left(\chi_{1} \cdot \chi_{2}\right) \mid H\left(e_{P}\right)=\left(\chi_{1} \mid H\left(e_{P}\right)\right) \cdot\left(\chi_{2} \mid H\left(e_{P}\right)\right)=h\left(\chi_{1}\right) \cdot h\left(\chi_{2}\right)$ so that $h$ is a homomorphism. To show $h$ is an isomorphism, we show each $\varphi$ in $\left(\hat{H}\left(e_{P}\right), T\right)$ may be extended, uniquely, to a $\chi$ in $\sigma(P)$. To

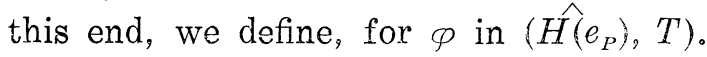

$$
\chi= \begin{cases}z, & \text { on } S \backslash P, \\ \varphi \circ r_{p} & \text { on } P .\end{cases}
$$

This is continuous because $r_{P}$ is continuous and $P$ is open and closed. A routine verification shows that $\chi$ is an extension of $\varphi$ to an element in $\sigma(P)$. Such an extension is unique as we shall now see. If $\chi^{\prime}$ is any element in $\sigma(P)$ with $\chi^{\prime} \mid H\left(e_{P}\right)=\varphi$, then $\chi^{\prime}(x)=z=\chi(x)$ for all $x$ in $S \backslash P$ and $\chi^{\prime}(x)=\chi^{\prime}(x) \cdot u=\chi^{\prime}(x) \cdot \chi^{\prime}\left(e_{P}\right)=\chi^{\prime}\left(x e_{P}\right)=\varphi\left(x e_{P}\right)=$ $\varphi \circ r_{p}{ }_{P}(x)=\chi(x)$, for all $x$ in $P$. Therefore, $h$ is an isomorphism of $\sigma(P)$ onto $\left(H\left(e_{P}\right), T\right)$. It remains to show, in the case $T \subset C$, that $h: \sigma(P) \rightarrow \hat{H\left(e_{P}\right)}$ is also a homeomorphism. This follows from the fact that $h$ is one-to-one, continuous and that $\hat{H\left(e_{P}\right)}$ is discrete [7].

COROLlaRY. If $S$ satisfies the hypotheses of Theorem 2, and if $S$ is connected, then $\mathscr{P}=\{S, \square\}$ and hence $(S, T)^{\wedge}=\left(\hat{H\left(e_{s}\right)}, T\right) \cup\{0\}=$ $\left(H\left(e_{s}\right), T\right)^{\wedge}$.

The author is greatly obliged to Professor A. D. Wallace for his encouragements.

\section{BIBLIOGRAPHY}

1. A. H. Clifford, Semigroups admitting relative inverses, Annals of Math. $\mathbf{4 2}$ (1941), 1037-1049.

2. H. Cohen, H. S. Collins, Affine semigroups, Trans. Amer. Math. Soc. 93 (1959), 97-113. 
3. M. P. Drazin, Pseudo-inverses in associative rings and semigroups, Amer. Math. Mon. Vol. 65 (1958), 506-514.

4. E. Hewitt, and H. S. Zuckerman, Finite dimensional convolution algebras, Acta Math. 93 (1955), 67-119.

5. G. Losey, and H. Schneider, Group membership in ring and semigroups, Pacific J. Math. 11 (1961), 1089-1098.

6. W. D. Munn, Pseudo-inverses in semigroups, Proc. Cambr. Phil. Soc. 57 (1961), 247-250.

7. L. S. Prontrjagin, Topological groups, Princeton (1939).

8. D. Rees, On semi-groups, Proc. Cambr. Phil. Soc. 36 (1940), 387-400.

9. S. Schwarz, The theory of characters of finite commutative semigroups, Czech. Math. J. 4 (79), (1954), 219-247.

10. The theory of characters of commutative Hausdorff bicompact semigroups, Czech. Math. 6 (81), (1956), 330-361.

11. A. D. Wallace, The structure of topological semigroups, Bull. Amer. Math., 61 (1955), 95-112.

12. - Relation-Theory (Lecture Notes), University of Florida, (1963-1964).

13. L. E. Ward, Jr. Partially ordered topological spaces, Proc. Amer. Math. Soc. 5 (1954), 141-161.

ACAdEMIa Sinica, Formosa

The University of SOUTh Florida 


\title{
PACIFIC JOURNAL OF MATHEMATICS
}

\author{
EDITORS
}

\author{
H. SAmelson \\ Stanford University \\ Stanford, California \\ R. M. Blumenthal \\ University of Washington \\ Seattle, Washington 98105
}

\author{
J. DugundjI \\ University of Southern California \\ Los Angeles, California 90007
}

*Richard Arens

University of California

Los Angeles, California 90024

\section{ASSOCIATE EDITORS}
E. F. BECKENBACH
B. H. NeUmanN
F. WOLF
K. YoSIDA

\section{SUPPORTING INSTITUTIONS}

\author{
UNIVERSITY OF BRITISH COLUMBIA \\ CALIFORNIA INSTITUTE OF TECHNOLOGY \\ UNIVERSITY OF CALIFORNIA \\ MONTANA STATE UNIVERSITY \\ UNIVERSITY OF NEVADA \\ NEW MEXICO STATE UNIVERSITY \\ OREGON STATE UNIVERSITY \\ UNIVERSITY OF OREGON \\ OSAKA UNIVERSITY \\ UNIVERSITY OF SOUTHERN CALIFORNIA
}

\author{
STANFORD UNIVERSITY \\ UNIVERSITY OF TOKYO \\ UNIVERSITY OF UTAH \\ WASHINGTON STATE UNIVERSITY \\ UNIVERSITY OF WASHINGTON \\ * * * * \\ AMERICAN MATHEMATICAL SOCIETY \\ CALIFORNIA RESEARCH CORPORATION \\ SPACE TECHNOLOGY LABORATORIES \\ NAVAL ORDNANCE TEST STATION
}

Mathematical papers intended for publication in the Pacific Journal of Mathematics should by typewritten (double spaced). The first paragraph or two must be capable of being used separately as a synopsis of the entire paper. It should not contain references to the bibliography. No separate author's resumé is required. Manuscripts may be sent to any one of the four editors. All other communications to the editors should be addressed to the managing editor, Richard Arens, at the University of California, Los Angeles, California 90024.

50 reprints per author of each article are furnished free of charge; additional copies may be obtained at cost in multiples of 50 .

The Pacific Journal of Mathematics is published quarterly, in March, June, September, and December. Effective with Volume 13 the price per volume (4 numbers) is $\$ 18.00$; single issues, $\$ 5.00$. Special price for current issues to individual faculty members of supporting institutions and to individual members of the American Mathematical Society: $\$ 8.00$ per volume; single issues $\$ 2.50$. Back numbers are available.

Subscriptions, orders for back numbers, and changes of address should be sent to Pacific Journal of Mathematics, 103 Highland Boulevard, Berkeley 8, California.

Printed at Kokusai Bunken Insatsusha (International Academic Printing Co., Ltd.), No. 6, 2-chome, Fujimi-cho, Chiyoda-ku, Tokyo, Japan.

PUBLISHED BY PACIFIC JOURNAL OF MATHEMATICS, A NON-PROFIT CORPORATION

The Supporting Institutions listed above contribute to the cost of publication of this Journal, but they are not owners or publishers and have no responsibility for its content or policies.

* Basil Gordon, Acting Managing Editor until February 1, 1966. 


\section{Pacific Journal of Mathematics}

\section{Vol. 15, No. $4 \quad$ December, 1965}

Robert James Blattner, Group extension representations and the structure space ........... 1101

Glen Eugene Bredon, On the continuous image of a singular chain complex .............. 1115

David Hilding Carlson, On real eigenvalues of complex matrices .................... 1119

Hsin Chu, Fixed points in a transformation group ............................. 1131

Howard Benton Curtis, Jr., The uniformizing function for certain simply connected Riemann

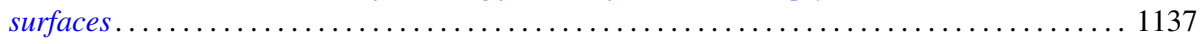

George Wesley Day, Free complete extensions of Boolean algebras................... 1145

Edward George Effros, The Borel space of von Neumann algebras on a separable Hilbert

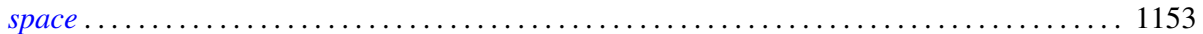

Michel Mendès France, $A$ set of nonnormal numbers ......................... 1165

Jack L. Goldberg, Polynomials orthogonal over a denumerable set ................ 1171

Frederick Paul Greenleaf, Norm decreasing homomorphisms of group algebras . . . . . . . . 1187

Fletcher Gross, The 2-length of a finite solvable group ........................ 1221

Kenneth Myron Hoffman and Arlan Bruce Ramsay, Algebras of bounded sequences ........ 1239

James Patrick Jans, Some aspects of torsion . . . . . . . . . . . . . . . . . . . . . . . 1249

Laura Ketchum Kodama, Boundary measures of analytic differentials and uniform

approximation on a Riemann surface ............................... 1261

Alan G. Konheim and Benjamin Weiss, Functions which operate on characteristic

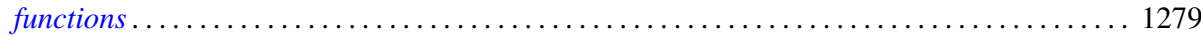

Ronald John Larsen, Almost invariant measures ............................ 1295

You-Feng Lin, Generalized character semigroups: The Schwarz decomposition ............ 1307

Justin Thomas Lloyd, Representations of lattice-ordered groups having a basis . . . . . . . . 1313

Thomas Graham McLaughlin, On relative coimmunity ....................... 1319

Mitsuru Nakai, $\Phi$-bounded harmonic functions and classification of Riemann surfaces ....... 1329

L. G. Novoa, On n-ordered sets and order completeness ..................... 1337

Fredos Papangelou, Some considerations on convergence in abelian lattice-groups . . . . . . . 1347

Frank Albert Raymond, Some remarks on the coefficients used in the theory of homology

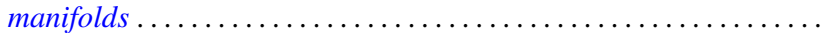

John R. Ringrose, On sub-algebras of a $C^{*}$-algebra .

Jack Max Robertson, Some topological properties of certain spaces of differentiable

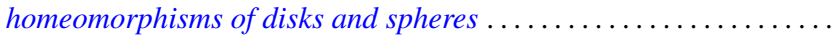

Zalman Rubinstein, Some results in the location of zeros of polynomials

Arthur Argyle Sagle, On simple algebras obtained from homogeneous general Lie triple systems. . . .

Hans Samelson, On small maps of manifolds ............................... 1401

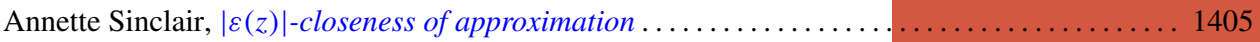

Edsel Ford Stiel, Isometric immersions of manifolds of nonnegative constant sectional curvature

Earl J. Taft, Invariant splitting in Jordan and alternative algebras ................. 1421

L. E. Ward, On a conjecture of R. J. Koch . . . . . . . . . . . . . . . . . . . . . . . . . . . 1429

Neil Marchand Wigley, Development of the mapping function at a corner . . . . . . . . . . 1435

Horace C. Wiser, Embedding a circle of trees in the plane ....................... 1463

Adil Mohamed Yaqub, Ring-logics and residue class rings . . . . . . . . . . . . . . . . 1465

John W. Lamperti and Patrick Colonel Suppes, Correction to: Chains of infinite order and their application to learning theory ........................................ 1471

Charles Vernon Coffman, Correction to: Non-linear differential equations on cones in Banach

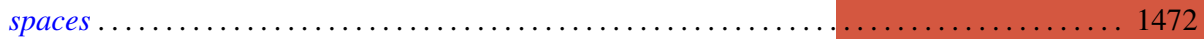

P. H. Doyle, III, Correction to: A sufficient condition that an $\operatorname{arc}$ in $S^{n}$ be cellular. . . . . . . . 1474

P. P. Saworotnow, Correction to: On continuity of multiplication in a complemented algebra 